\title{
The First Retinal Axons and Their Microenvironment in Zebrafish: Cryptic Pioneers and the Pretract
}

\author{
John D. Burrill and Stephen S. Easter, Jr. \\ Department of Biology and Neuroscience Program, University of Michigan, Ann Arbor, Michigan 48109-1048
}

The initial development of the optic tract was studied with light and electron microscopy in the zebrafish (Danio rerio). Intraocular injections of the fluorescent marker, 1,1'-dioctadecyl-3,3,3',3' tetramethylindocarbocyanine perchlorate (dii), labeled retinal axons and growth cones anterogradely, and injections of dil into the optic chiasm labeled retinal ganglion cells retrogradely. Labeled tissue was photoconverted and examined electron microscopically.

The ventronasal retinal quadrant produced the first growth cones. They were the first growth cones in the optic stalk. The leading retinal growth cones, typically 4-10 in number, advanced alongside the tract of the postoptic commissure but rarely sent filopodia into it and never wrapped its axons. Instead, the retinal growth cones followed a pretract, a subpial region that was morphologically distinct from its surroundings and extended out in front of the leading growth cones, presaging the optic tract. Thus, the retinal growth cones, previously thought to be followers of preexisting axons, are actually cryptic pioneers whose proximity to the earlier axons masks their pioneering nature. We suggest that cryptic pioneers and pretracts are probably common elsewhere in the nervous system.

[Key words: zebrafish, growth cone, optic tract, retina, tract of the postoptic commissure, pioneer axons]

Tracts are generally thought to form in two phases. Initially, the pioneering growth cones traverse axon-free tissue, presumably detecting cues in or around the cells along the way, and later, follower growth cones advance along the axons left by the pioneers (Speidel, 1933; Bate, 1976; Bodick and Levinthal, 1980; Ho and Goodman, 1982; Keshishian and Bentley, 1983; Kuwada, 1986). The question of whether the pioneer neurons are uniquely able to make the initial navigation has been addressed many times by ablating them and then determining if the followers can still find their way. The answer has come out both ways--some can (Eisen et al., 1989; Pike and Eisen, 1990), and some cannot (Edwards et al., 1981; Kuwada, 1986; Klose and

\footnotetext{
Received Aug. 2, 1994; revised Oct. 20, 1994; accepted Oct. 26, 1994.

We thank Ms. Celeste Malinoski for her excellent technical assistance at all stages of the project, Dr. Steve Wilson for guidance and instruction at the early stages, and Drs. Janet Braisted, Dave Cameron, Riva Marcus, Pamela Raymond, Kathryn Tosney, and Steve Wilson for comments on the manuscript This work was supported by a research grant from the National Eye Institute to SSE (EY-00168) and training support to J.D.B. from the National Institute for Mental Health, the National Eye Institute, and the Rackham Graduate School of the University of Michigan.

Correspondence should be addressed to Dr. John D. Burrill, Molecular Neurobiology Laboratory-G, Salk Institute, 10010 North Torrey Pines Road, La Jolla, CA $9203 \%$.

Copyright $(\mathcal{O} 1995$ Society for Neuroscience $0270-6474 / 95 / 152935-13 \$ 05.00 / 0$
}

Bentley; 1989), depending on the particular system studied. In this study, we use the term "pioneer" to indicate only that the growth cone is the first one in the area, and does not advance along preexisting axons, as "followers" do.

Recent descriptions of the first tracts in vertebrate brains have rekindled interest in the relationship of pioneers and followers. In zebrafish, the presumptive fore- and midbrains have only five tracts and three commissures by $24 \mathrm{hr}$ postfertilization (hr) (roughly a third of the way to hatching). All are small and compact, leaving most of the brain free of axons. By $48 \mathrm{hr}$, the number of axons has increased nearly a 100 -fold, but only a few new tracts and commissures have appeared, as most new axons were added alongside the preexisting ones (Wilson et al., 1990). This suggests that the old axons may guide the new ones, and the term used to describe the early network - the "axon scaffold"-(Easter and Taylor, 1989; Wilson et al., 1990) was chosen to imply such a function. Detailed studies of the formation of early tracts in both insects (Raper et al., 1983; Bastiani et al., 1984, 1986; du Lac et al., 1986) and zebrafish (Wilson and Easter, 1991a,b) supported that view, as many of the follower growth cones wrapped the axons already in place.

The microenvironment of pioneering growth cones is structurally complex, as it consists of the colonnade of neuroepithelial cells that extend from the central canal (the presumptive ventricle) to the surrounding basal lamina (part of the presumptive pia). The growth cones and the axons that they produce are always superficial, much closer to the basal lamina than to the central canal (Easter and Taylor, 1989; Wilson et al., 1991a,b). The link between the neuroepithelial endfect and the basal lamina is rarely broken, as virtually all pioneering growth cones and axons are separated from the hasal lamina by endfeet (Wilson and Easter, 1991a,b). Thus, growth cones must weave around the columnar neuroepithelial cells, following a route that is structurally analogous to the advance of a snake through an array of bowling pins. But the serpentine analogy fails in detail because growth cones are usually not pencil-shaped like the head of a snake. Instead, they are flattened perpendicular to the long axis of the neuroepithelial cclls, have a diameter cqual to or greater than these cells, and extend multiple filopodia around them. To match this gorgonian morphology, the snake would need several heads, each independently motile, each extending around different bowling pins. In contrast, the follower growth cones have a simpler task because they can simply fasciculate with and advance along preexisting axons (Weiss, 1941), particularly if the pioneer expresses adhesion molecules that the followers recognize (Patel et al., 1987; Dodd et al., 1988). The molccular differences between pioneers and followers are unknown, but the anatomical distinction between the two seems 


\begin{tabular}{llll}
\hline Table 1. & \multicolumn{2}{l}{ Classes of embryos } \\
Class & Age (hr) & Prim stage & Location of leading retinal growth cones \\
\hline 1 & $32-34$ & 18.0 & Entering optic stalk \\
2 & $33-35$ & $19.0-21.5$ & Midline \\
3 & $34-36$ & $20.0 \pm 23.0$ & Lateral surface, ventral/rostral to supraoptic tract \\
4 & $36-45$ & $>23.0$ & Lateral surface, dorsal/caudal to supraoptic tract \\
5 & $45-54$ & - & Rostral optic tectum \\
6 & $>60$ & - & Caudal optic tectum
\end{tabular}

The "prim stage" is a measure derived from the position of the lateral line primordium (Westerfield, 1989). The location of the supraoptic tract is shown in Figure 3.

quite clear and dichotomous: pioneer growth cones navigate between the basal (subpial) endfeet of columnar neuroepithelial cells (Wilson and Easter, 1991a,b), thus creating a potential way through the colonnade, and followers associate with preexisting axons to form a tract.

The tract of the postoptic commissure (TPOC) is part of the early scaffold in all four vertebrate classes that have been examined (reviewed by Easter et al., 1994). In the zebrafish, it is pioneered at about $16 \mathrm{hr}$ by caudally directed growth cones arising from neurons at the base of the optic stalk (Ross et al., 1992). About $16 \mathrm{hr}$ later, growth cones from the contralateral retina have crossed the midline and begun to grow along the dorsorostral border of the TPOC toward the presumplive tectum (Stuermer, 1988; Wilson et al., 1990; Burrill and Easter, 1994). The relation between retinal growth cones and the TPOC was not examined in zebrafish, but in Xenopus, labeled retinal growth cones were seen in electron micrographs to wrap around unlabeled preexisting axons presumed to be part of the TPOC (Easter and Taylor, 1989). This was interpreted as evidence for guidance of retinal axons by the TPOC, but Cornel and Holt (1992) disputed this interpretation, as they reported that retinal axons reached the optic tectum in experimental amphibian embryos that lacked the TPOC.

In this article, we investigate retinal growth cones in normal zebrafish, with particular attention to the question of whether they associate with the TPOC axons. We find that they do not; they occasionally extend a filopodium into the TPOC, but they do not wrap its axons. Thus, although they are not the first growth concs in the vicinity, they are the first in their microregion, and they advance without wrapping predecessors. For these reasons, the retinal axons do not fit easily in either of the classical categories of pioneer or follower that were defined above. We call them "cryptic pioneers" because their pioneering nature is masked by their proximity to a preexisting tract. The

\section{Table 2. Numbers and treatments of fish injected with diI}

\begin{tabular}{rlll} 
Age $(\mathrm{hr})$ & Injected & $\begin{array}{l}\text { Electron } \\
\text { microscopy }\end{array}$ & Plane of section \\
\hline $30-32$ & 65 eye, 32 midline & 0 & - \\
$>32-36$ & 99 eye & 5 & 3 sagittal, 2 horizontal \\
$37-42$ & 86 eye & 5 & 1 sagittal, 4 horizontal \\
\hline
\end{tabular}

The injections into the eye labeled axons anterogradely and those into the midline labeled retinal ganglion cells retrogradely. Those sectioned for electron microscopy were sectioned sagittally to view labeled axons at the midline, while those sectioned "horizontally" (see Fig. 5 for an example of a "horizontal" plane of section) were used to examine labeled axons advancing on the lateral wall of the brain. growth cones of the cryptic pioneers advance in a separate region in which the pial ends of the neuroepithelial cells have assumed a filamentous texture, and, thus, present an environment that is unlike either of those that were associated with classically defined pioneers or followers. This unique environment occupies a thin lamina, 5-20 $\mu \mathrm{m}$ wide and $1-2 \mu \mathrm{m}$ deep, adjacent to the rostral border of the TPOC. This region lies distal to the retinal growth cones, in the direction of their incipient growth, and presages a significant portion of the optic tract, for which reason we call it the "pretract." It offers a third environment for axonal elongation in the CNS, a guided pathway for cryptic pioneers. We suggest that pretracts and cryptic pioneers probably exist elsewhere in the CNS in association with early tracts.

\section{Materials and Methods}

Embryos. Zebrafish were obtained from our own colony, using standard methods described elsewhere (Wilson et al., 1990). Embryos were collected as blastulas approximately $1 \mathrm{hr}$ after fertilization and the cells in each blastula were counted. The time of fertilization was calculated from the number of cells in the blastula, on the assumption that the first cell division takes place approximately $40 \mathrm{~min}$ after fertilization, and each subsequent division takes place approximately every $15 \mathrm{~min}$ thereafter (Westerfield, 1989). At $18 \mathrm{hr}$, phenylthiocarbamide [1-phenyl-2thiourea (Sigma)] was added to the medium $(0.2 \mathrm{~mm})$ to block melanin formation. This enhanced the visibility of labeled axons in whole mounts. Some of the embryos were also staged at the time of fixation according to a morphological criterion, the segmental position of the migrating lateral line primordium ("prim stage"; Metcalfe, 1985: Westerfield, 1989). Table 1 summarizes the ages and stages of fish used in this study.

DiI labeling. Embryos of various ages (Table 2) were fixed overnight in $4 \%$ phosphate-buffered formalin (pH 7.4) and labeled the following day with diI (Molecular Probes) (Honig and Hume, 1986; Godement et al., 1987). The dil was dissolved in $N, N$-dimethylformamide $(2.5 \mathrm{mg} /$ $\mathrm{ml}$ ), pressure injected intraocularly (to label retinal axons and growth cones anterogradely) or into the midline at the presumed location of the optic chiasm (to label retinal ganglion cells retrogradely), and allowed to transport overnight at $4^{\circ} \mathrm{C}$. The embryos that had received chiasmatic injections were viewed intact, and the skin and eyes were removed from the embryos that had been injected intraocularly. All were viewed with rhodamine optics under epifluorescence. The diI fluorescence was photoconverted to a permanent, electron-dense reaction product by photoexcitation of the dye in the presence of $0.08 \%$ DAB (McConnell et al., 1989). The embryos were then cleared in glycerin, whole mounted between two coverslips, and viewed in differential interference optics. They were photographed and/or drawn through a camera lucida attachment. Intraocular injections produced labeled optic tracts of variable length. The labeled axons gencrally cxtended farther in the older embryos, but the correlation with age was only approximate. We classify the embryos according to the position of the most advanced growth cone according to the criteria given in Table 1.

Immunocytochemistry. Embryos 36-38 hr old $(n=15)$ were double labeled with intraocular diI and an antibody, 6-11B-1, against acetylated alpha tubulin (Piperno and Fuller, 1985). First, the diI was intraocularly injected to label the optic axons as described above, and then photo- 
converted to yield a brown reaction product. The whole mount was labeled with the primary antibody and a peroxidase-coupled secondary antibody. The DAB reaction was carried out in the presence of saturating amounts of cobalt chloride and nickel ammonium sulphate to give a blue reaction product (Adams, 1980).

Electron microscopy. DiI-labeled embryos fixed in $4 \%$ formalin were traced and/or photographed, fixed sequentially in phosphate-buffered $3 \%$ glutaraldehyde for $2 \mathrm{hr}$, and in phosphate-buffered 1 or $2 \%$ osmium tetroxide for 1-2 hr, block stained in uranyl acetate, and embedded in epon-araldite. To examine the environment of the dil-labeled growth cones, the embryos were sectioned beginning proximal to the labeled growth cones (i.e., on the side toward the retina). Initially, $1 \mu \mathrm{m}$ thick sections were cut, stained with toluidine blue, and examined light microscopically to find the labeled optic axons. Periodically, a set of serial ultrathin sections (4-60 sections approximately $0.10-0.15 \mu \mathrm{m}$ thick) were cut, mounted on formvar-supported one-hole grids, and viewed, unstained by lead, on a Philips 300 electron microscope. This quasiserial sectioning, carried out with frequent reference to the block and the sketch of that particular embryo, assured that the growth cone and its environment were extensively sampled. In all cases, the last set of ultrathin sections contained no labeled processes, indicating that tissue out in front of the growth cones had been sampled. Table 2 gives the ages and numbers of fish and their planes of section.

Photomosaics of electron micrographs of the labeled retinal axons or growth cones and their surrounding environment were assembled. To compare the processes in pretract and TPOC, transects perpendicular to the pial surface were drawn at intervals of $2.8 \mu \mathrm{m}$, and all the membrane-bound profiles that they touched were measured with a Mop-3 digitizing tablet (Zeiss). The median area of the profiles crossed by cach transect was determined. The median was used rather than the mean, which is too sensitive to the rare outliers, often $20-40 \times$ the median. The published calibration of the microscope was assumed, and no allowance was made for shrinkage.

\section{Results}

Intraocular injections at 30-72 hr never labeled somata in the brain, from which we conclude that no retinopetal axons exist prior to $72 \mathrm{hr}$. This is in contrast to the recent report in ferret, in which retinopetal axons preceded retinofugal ones in the optic stalk (Reese and Geller, 1994).

\section{The first retinal axons and their somata}

The optic nerve and tract were formed by a small number of leading growth cones. In embryos in which the leading growth cones had advanced to the ventral midline (class $2, n=4$ ), sagittal sections showed that the labeled axons formed a small fascicle on the ventrocaudal end of the optic stalk (Fig. 1). The labeled axons could not be counted directly, because the spread of the photo-reaction product obscured plasma membranes, but this number was estimated by determining the average area of an individual unlabeled retinal axon from the uninjected eye and calculating the number of them that would occupy an area equivalent to that of the reaction product. The estimate ranged from 4 to 10 . In whole-mounted embryos of classes 3 and $4(n=9$ and $n=16$, respectively), a comparably small group of lcading axons and growth cones were ahead of a larger group, generally by about $50 \mu \mathrm{m}$, confirming Stuermer (1988) (see Fig. 3).

The leaders originated from ventronasal retina, and were joined later by axons from dorsal, then temporal, retina. Injections of dil were made into the presumptive optic chiasm of 32$35 \mathrm{hr}$ embryos, the ages that should include mostly class 2 embryos. In some retinas, no cells were labeled, presumably because the injection missed the midline axons or because the axons had not reached the midline. In those retinas $(n=32)$ with labeled cells, the cells lay in a cluster of 4-10 in the ventronasal quadrant of the retina, adjacent to the embryonic fissure (Fig. 2A,B). Similar injections in $35-45$ hr embryos, presumably classes 3 and $4(n=30)$, labeled more ganglion cells arrayed in an arc that always included the ventronasal quadrant, and fanned out dorsotemporally (Fig. 2C), and injections in embryos of classes 5 and $6(n=31)$ labeled many more cells throughout the entire retina (Fig. $2 E$ ). Thus, the area of retina contributing axons was initially a small ventronasal patch that expanded dorsally to form an arc that closed the circle at the embryonic fissure.

The morphologies of the ganglion cells matured as the retinal growth cones advanced. Of the 227 cells labeled in embryos of classes 2 and 3 , only 4 had an apical process extending to the outer limiting membrane (the retinal equivalent of the boundary of the central canal), as neuroepithelial cells would be expected to have. Most (143) lacked apical processes of any sort (Fig. $2 B$ ), and the remainder ( 80$)$ had one to three unbranched processes, typically 3-5 $\mu \mathrm{m}$ long (not shown), that were probably the beginnings of dendrites. Such processes were more common in class 4 embryos (Fig. $2 D$ ), and in class 5 , the dendrites were clearly stratified in the presumptive inner plexiform layer (Fig. $2 F$ ). Displaced ganglion cells, those with somata located on the scleral side of the dendritic arborizations, were very rare. These observations suggest that the withdrawal of the apical process and the initial outgrowth of axons and dendrites all occurred within a couple of hours, and that the axon extended before the dendrites. Subsequently, dendritic and axonal differentiation occurred simultaneously.

\section{The retinal growth cones and the axonal scaffold}

The leading retinal growth cones $(n=45)$ were examined in whole mounts of class 1-4 embryos, and their structures were relatively simple. They had an average of 4.7 filopodia, ranging in length from 1-20 $\mu \mathrm{m}$, most commonly 4-5 $\mu \mathrm{m}$. Neither the number nor the length of the filopodia varied systematically with position between chiasm and tectum.

The nonretinal axonal scaffold was relatively constant during the period (33-45 hr) during which the retinal growth cones advanced from chiasm to tectum. Figure 3 shows a class 4 embryo that was doubly labeled with intraocular diI, to label the retinal axons and growth cones, and with the antibody to acetylated alpha-tubulin (6-11B-1) to label all other axons. The immunocytochemistry was carried out with $\mathrm{Cu}^{2+}$ and $\mathrm{Ni}^{2+}$ ions present, to produce a blue-gray reaction product that was easily distinguished from the brown photoconverted axons. Figure $3 A$ shows the axonal scaffold without the retinal fibers; note that all the tracts are tightly fasciculated except the tract of the habenular commissure (THC). It was narrow dorsally, but broadened in middiencephalon, spreading out like a river delta. Figure $3 B$ represents the same embryo, with the scaffold shown in hatching and the retinal axons dark. As the more highly magnified inset shows, the retinal growth cones and axons seemed to overlap with the TPOC, but this could be illusory, a consequence of viewing a two-dimensional projection of a three-dimensional structure.

This possibility was checked electron microscopically. Individual embryos (classes 2-4) were injected intraocularly with dil, photoconverted, and drawn and/or photographed as whole mounts. Then they were examined electron microscopically. The embryos were sectioned in a plane that produced transverse sections of the retinal axons and growth cones, which were recognized by their dark reaction product. Semithin sections (1-2 $\mu \mathrm{m}$ thick) were interspersed with series of 4-40 ultrathin sections $(0.1-0.15 \mu \mathrm{m}$ thick).

In class 2 embryos $(n=3)$, those with their leading growth 


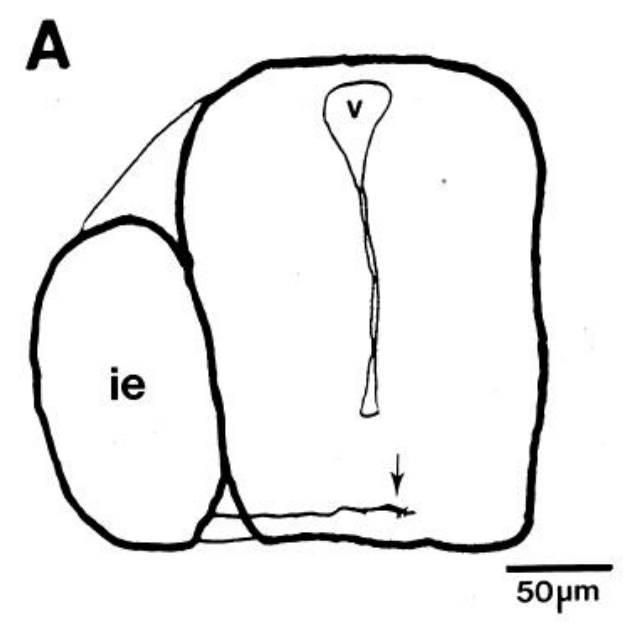

Figure 1. Retinal axons in class 2 embryos. $A$ shows a rostral view of a whole-mounted embryo, $B$ and $C$ show sagittal paramedian sections through the base of the optic stalk of the same embryo, and $D$ shows a sagittal section through the chiasm. $A$, Camera lucida drawing, dorsal up. The small bundle of labeled axons, led by a growth cone (arrow) extends from the injected eye to the midline. The uninjected eye was removed. $B$, Light micrograph, dorsal up, rostral left. The TPOC is evident as a nucleus-free zone with a fibrous texture. Bulging from the base of the neural tube, the optic stalk contains the fascicle of labeled axons on its ventrocaudal surface (arrow). $C$, Electron micrograph, same orientation as $B$. A more highly magnified view of a nearby section, showing that the fascicle is on the superficial surface in contact with the basal lamina (arrowheads). It contains two to five labeled axons (arrow) and four unlabeled ones (aster$i s k s$ ), a total of six to nine 9 axons. $D$, Electron micrograph, dorsal left, rostral down. A labeled leading growth cone near the midline contacts two unlabeled profiles slightly (asterisks), and wraps a third (arrow). The growth cone was separated from the TPOC, the left optic nerve, and the basal lamina (small arrowheads) by neuroepithelial endfeet. Contamination (large arrowheads) was not confused with labeled processes because it could not be traced in adjacent sections. ie, injected eye; $L O N$, left optic nerve; $n e$, neuroepithelial endfoot; $o s$, optic stalk; TPOC, tract of the postoptic commissure; $v$, ventricle.
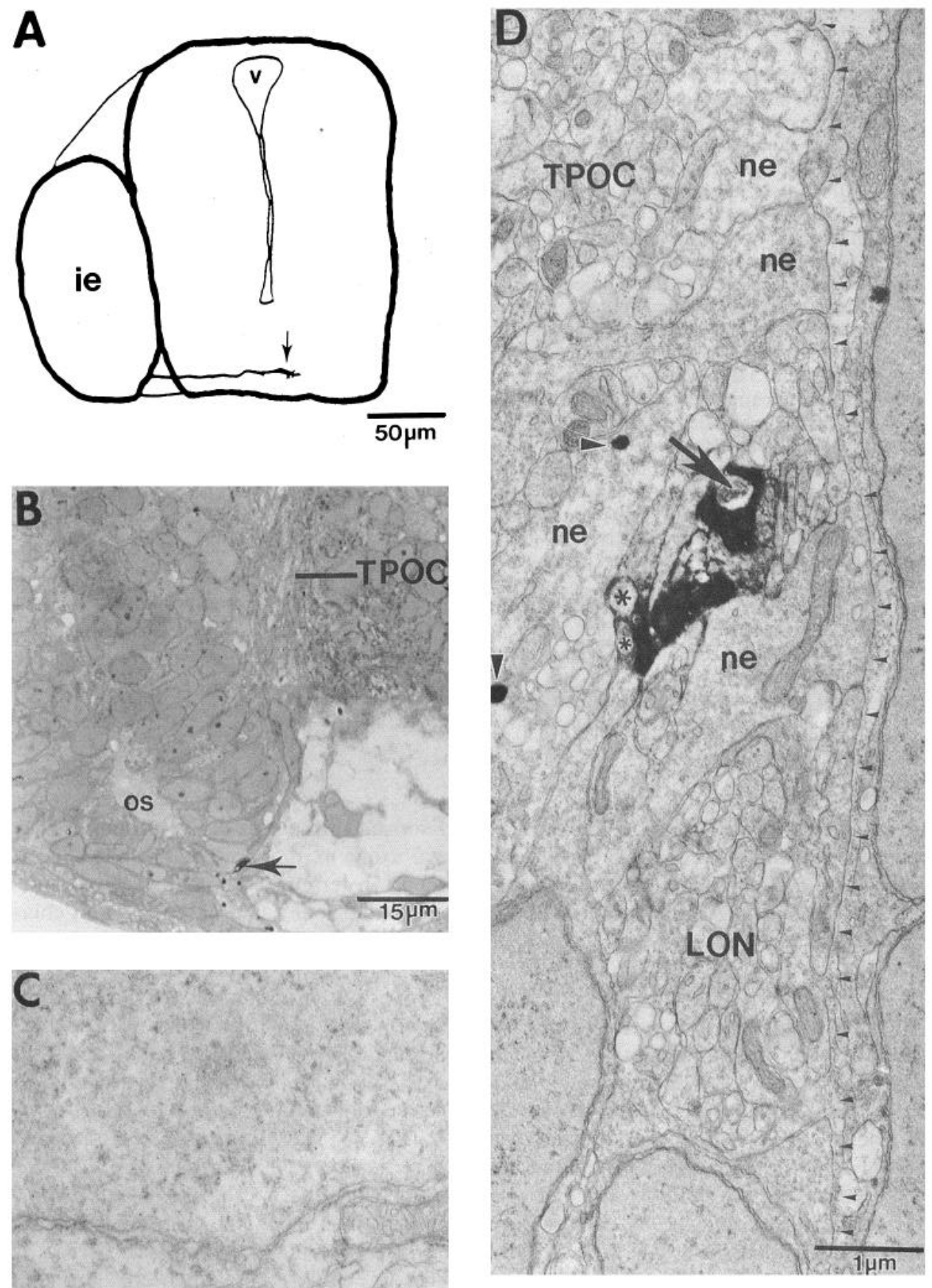

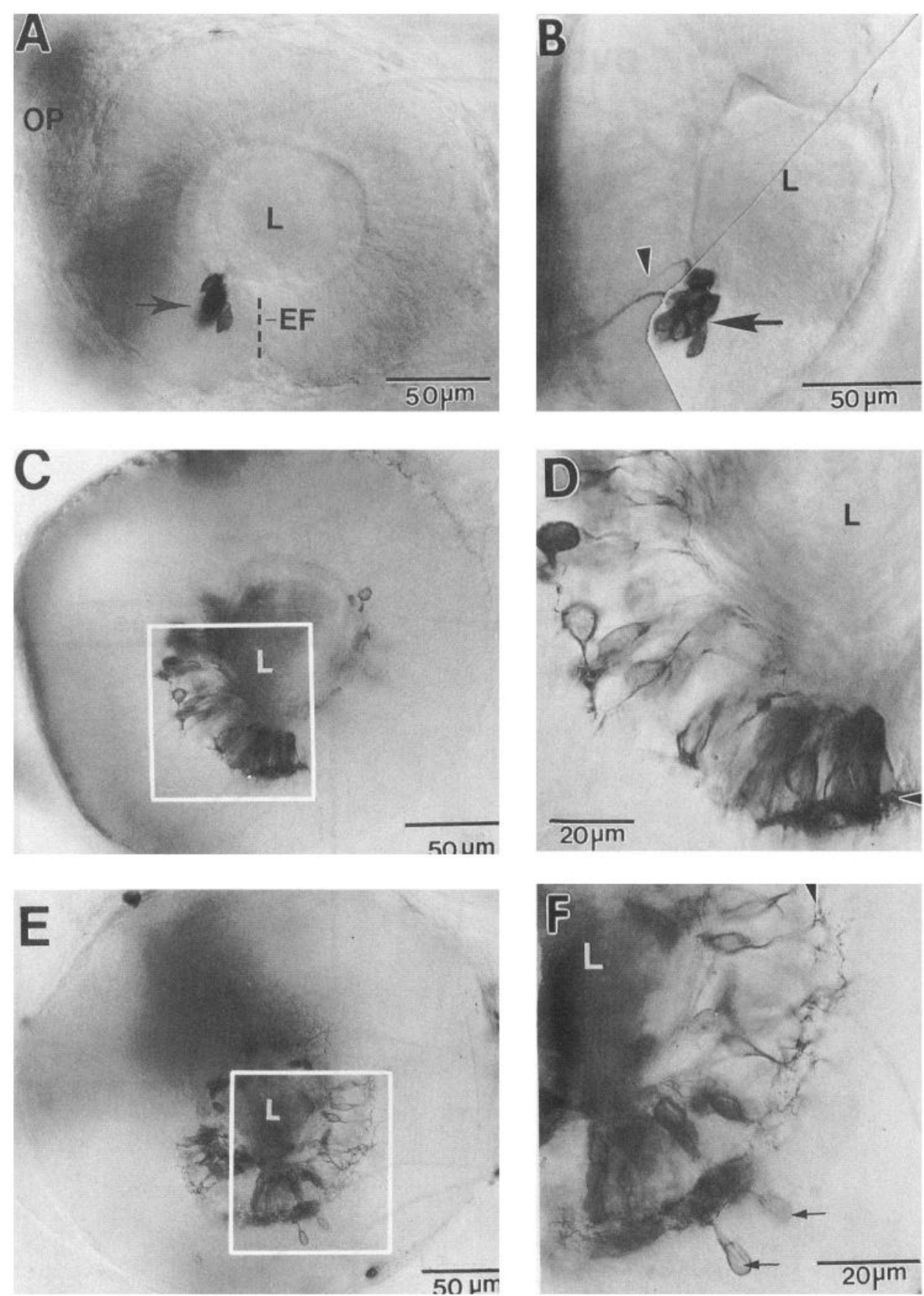

Figure 2. Retinal ganglion cells labeled retrogradely from midline injections in three embryos: class $2(A$ and $B)$, class $4(C$ and $D)$, and class $5(E$ and $F$ ), viewed in whole mounts. All panels except $B$ show a lateral view, with dorsal up, rostral left; $B$ shows a rostral view, with dorsal up, lateral right. $A$ and $B$, The labeled cells (arrow) are adjacent to the embryonic fissure in the ventronasal quadrant. The axons (arrowhead) exit directly into the optic stalk. $C$ and $D$, Labeled cells extended all around the arc centered on the lens, but the plane of focus emphasizes those in ventronasal retina. The box in $C$ indicates the field of $D$. Within the ventronasal quadrant, those somata adjacent to the embryonic fissure were densest and their stubby dendrites were most developed. $E$ and $F$, The labeled cells lie in a complete circle, although the plane of focus blurs those in dorsal retina. The box in $E$ gives the field of $F$. The dendrites are narrowly stratified (arrowheads). Two (rare) displaced ganglion cells are shown (arrows). cones around the midline, sagittal sections revealed that the leaders were separated from the TPOC by neuroepithelial processes and endfeet. Figure $1 D$ shows a near-midline section through the optic tract of the labeled eye and the optic nerve of the unlabeled eye. In this case, three neuroepithelial processes separate the growth cone and the TPOC, and adjacent sections showed that this separation was maintained over the entire length of the growth cone. In older embryos, the TPOC and optic tract remained separated, but the distance decreased, often to no more than a single attenuated process, $1 \mu \mathrm{m}$ or less in diameter (R. C. Marcus and S. S. Easter, Jr., unpublished observations).

In embryos of classes $3(n=1)$ and $4(n=4)$, the retinal growth cones and filopodia were also separated from the TPOC. In Figure $4 A$, the two leading retinal axons are separated ros- trally from the TPOC by about $20 \mu \mathrm{m}$, and examination of the other sections from this embryo showed no contact between retinal growth cones or filopodia and the TPOC axons, despite the impression gained from whole mounts such as the one in Figure 3. In all five embryos examined in this way, only two filopodia (both in the same class 4 embryo) contacted the TPOC. We conclude that the leading retinal growth cones do not fasciculate with the TPOC and, therefore, do not fit the standard definition of followers. They advance without using the preexisting axons as substrates, and they form a tract that is close to, but independent of, the TPOC. The proximity to the TPOC masks their pioneering behavior, and for this reason we call them "cryptic pioneers."

The retinal axons in Figure $4 A$ are surrounded by a matrix of 


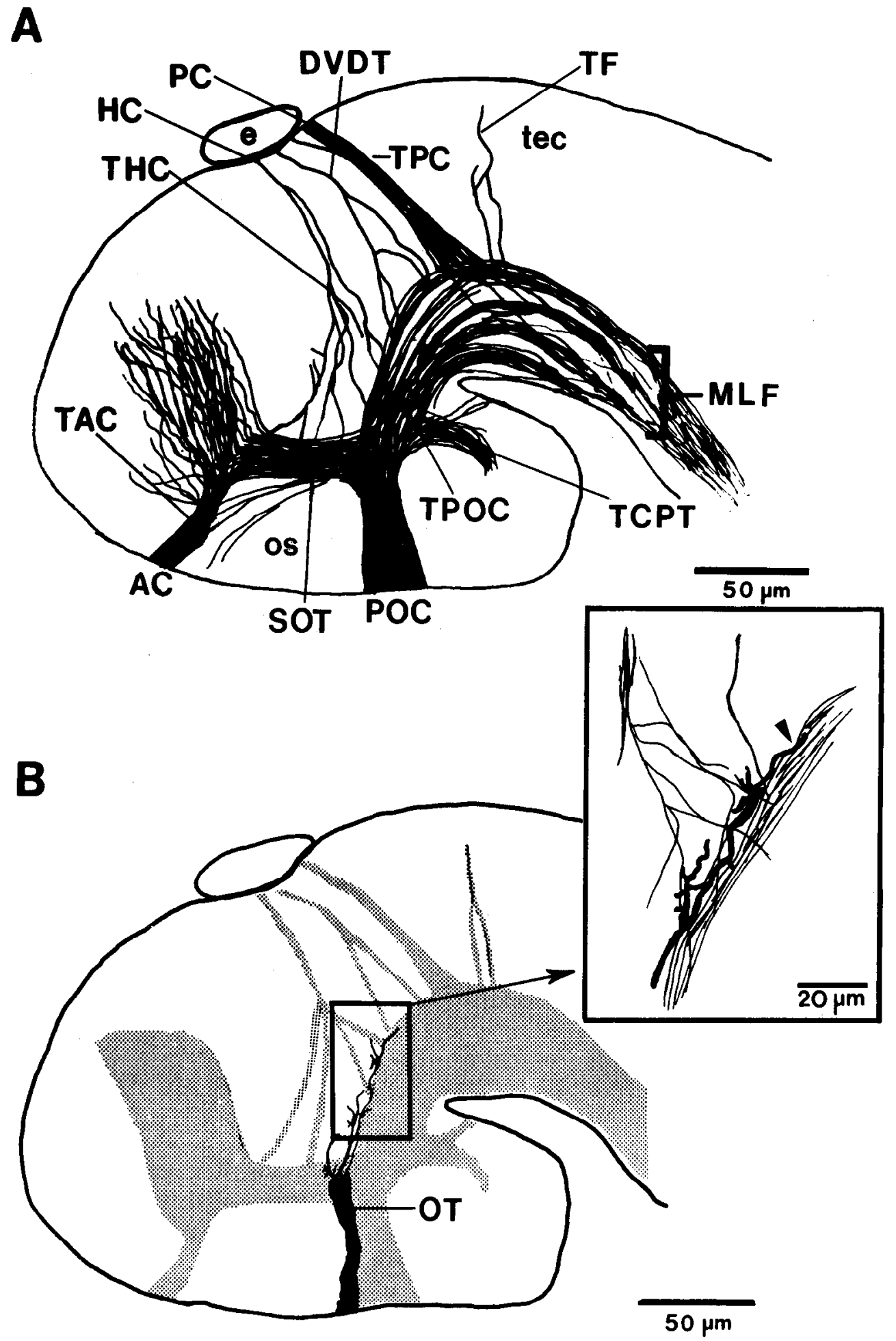

Figure 3. Class 4 embryo whole mount, doubly labeled to show optic and nonoptic axons. Camera lucida drawings; lateral views with rostral to the left, dorsal up. $A$, The axonal scaf fold, revealed by reaction with the antibody $6-11 \mathrm{~B}-1$, is shown in black. $B$, The same embryo as in $A$, but the scarfold is shown in hatching, and the diIlabeled optic fibers are black. The retinal axons lie along the rostral border of the TPOC in the same region that axons of the THC, and the DVDT join the TPOC. The inset shows a more detailed view of the relation of the two sets of axons. One filopodium of the leading growth cone seems to contact the TPOC (arrowhead). $A C$, anterior commissure; $D V D T$, dorsoventral diencephalic tract; $H C$, habenular commissure; $M L F$, medial longitudinal fasciculus; os, optic stalk; $p$, pineal gland (epiphysis); $P O C$, postoptic commissure; $T A C$, tract of the anterior commissure; TCPT, tract of the commissure of the posterior tuberculum; $T P C$, tract of the posterior commissure; $T P O C$, tract of the postoptic commissure; SOT, supraoptic tract; tec, presumptive optic tectum; $T F$, tectal fibers.

thin neuroepithelial processes in a space 1-5 $\mu \mathrm{m}$ deep, sandwiched between the basal cytoplasm of the somata on one side and the basal lamina on the other. This is a novel environment, different from the undifferentiated neuroepithelial colonnade that earlier studies of pioneers had revealed (Wilson and Easter, 1991a,b), and clearly not tract like, as most of its inclusions are not axonal. In Figure $4, B$ and $C$ show two more highly magnified views of this space, and illustrate that it is distinguished structurally by the presence of fine processes. At least some of these processes are derived from the underlying cells, as shown in Figure $4 C$, but we cannot rule out the possibility that some of the processes are from cells lateral to the pretract. As Figure 5 shows, this special region extends out in front of the retinal axons in the region where the optic tract will form. For that reason, we call it the pretract. It is one of three distinct subpial microenvironments that growth cones encounter. Figure 6 illustrates and contrasts them with one another.

Basal nuclear zone (Fig. 6A). In those regions of the brain with no tracts, many of the neuroepithelial nuclei extend all the way into the basal endfeet; and the endfeet are relatively simple, 

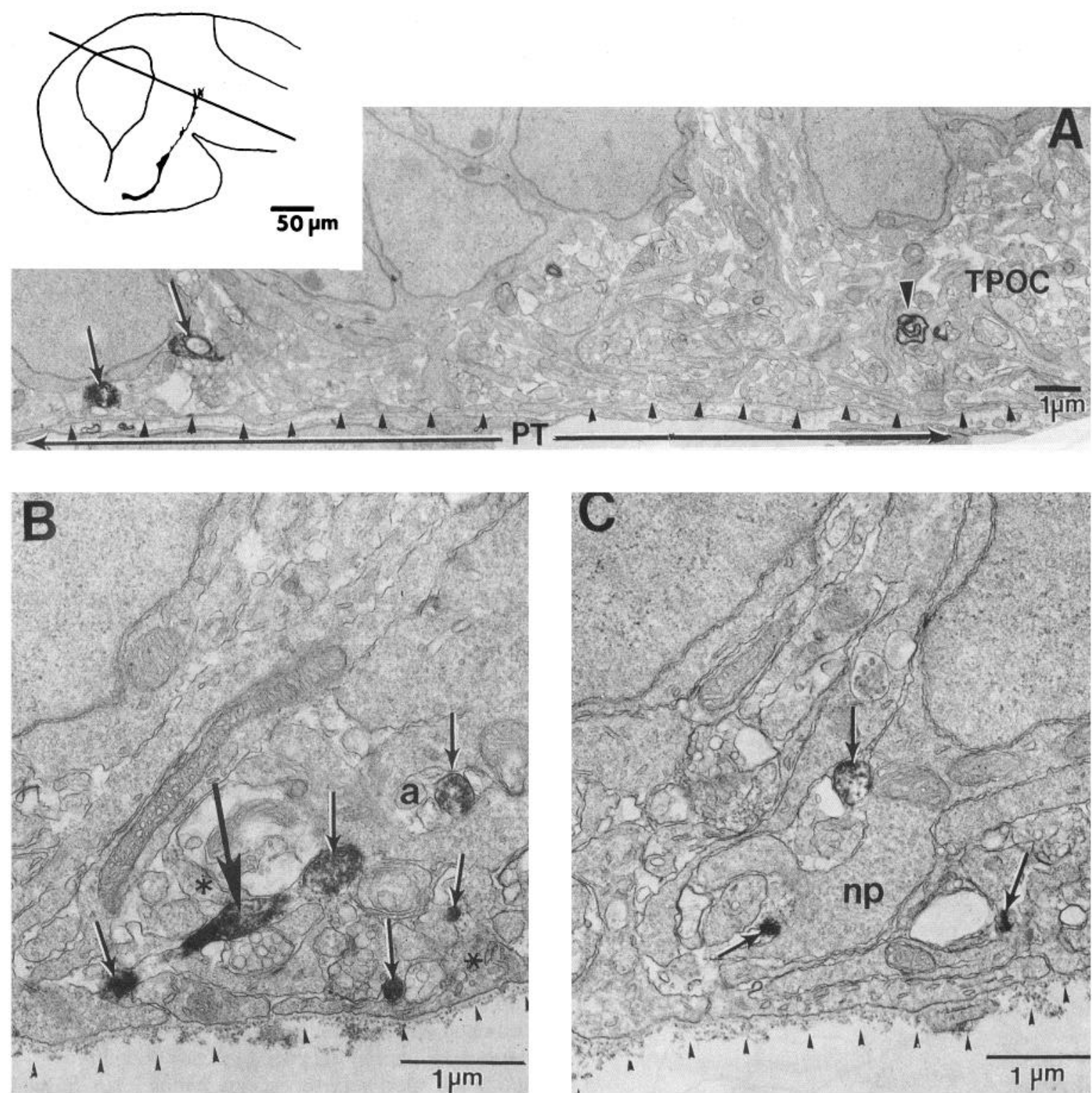

Figure 4. The pretract in class 4 embryos. Electron micrographs; rostral is to the left, medial, up. A, Section through a small part of the TPOC and all of the pretract $(P T)$, at the plane of section shown in the camera lucida drawing (inset). The TPOC, most of which is outside the picture to the right, is filled with axons and neuroepithelial processes, and the neuroepithelial nuclei are displaced 10-15 $\mu \mathrm{m}$ from the basal lamina (small arrowheads). In the pretract, adjacent to the rostral edge of the TPOC, the neuroepithelial nuclei are separated from the basal lamina by only about 1-4 $\mu \mathrm{m}$. Two dark (diI-labeled) leading optic axons (small arrows) are surrounded by neuroepithelial processes, including endfeet that separate them from the basal lamina. The labeled axons are easily distinguished from an artifactual "myelin body" (large arrowhead), which does not extend through serial sections. $B$ and $C$, More highly magnified views of the pretract in another embryo sectioned at the same orientation, but at a slightly more distal location than $A$. The section in $B$ passes through the distal part of the growth cone (large arrow) and several filopodia (small arrows), in a milieu of neuroepithelial processes. $C$. Same embryo as $B, 1 \mu \mathrm{m}$ more distal, showing three filopodia, one embraced by a thin neuroepithelial process $(n p)$ originating from an adjacent cell.

like capitals atop thick pillars. The basal nuclear zone exemplifies what we believe to be typical of the basal wall of the neural tube prior to the formation of tracts (Wilson and Easter, 1991a,b).

Tract (Fig. 6C). This is predominantly axonal; in the TPOC, hundreds to thousands of axons, median diameter $0.10 \mu \mathrm{m}$, are interleaved among radial processes emanating from the cells below. The identities of these cells are not certain, but we assume that they may include proliferative neuroepithelial cells, neurons, and perhaps glia. (We are uneasy with the use of the term, "radial glia," to describe neuroepithelial cells that extend from ventricle to pia, in the absence of some positive indication that they are glial.) Many of the radial cells in this region do express the astrocytic marker, glial fibrillary acidic protein (Marcus and Easter, 1990), but probably only transiently (R. C. Marcus and S. S. Easter, Jr., unpublished results.) In the tract, the neuroepithelial cell processes are T-shaped, formed from an attenuated radial process (a much thinner pillar than in the basal nuclear zone) and a broad endfoot flattened on the basal lamina. The nuclei of these cells are displaced as much as $10-12 \mu \mathrm{m}$ from the basal lamina to produce a subpial nucleus-free zone that is normally interpreted as a tract when 


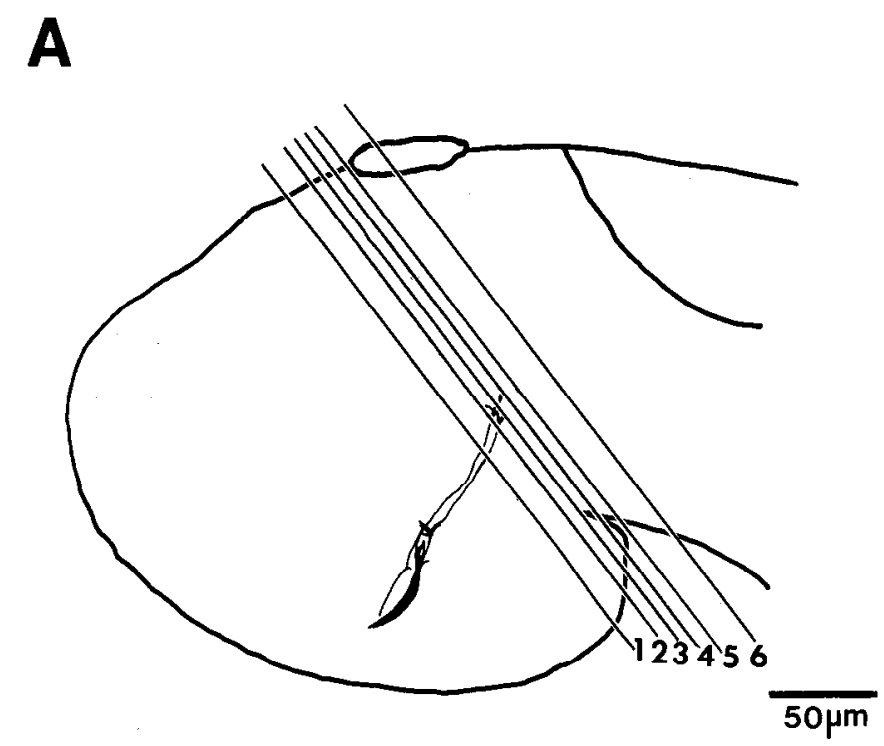

B

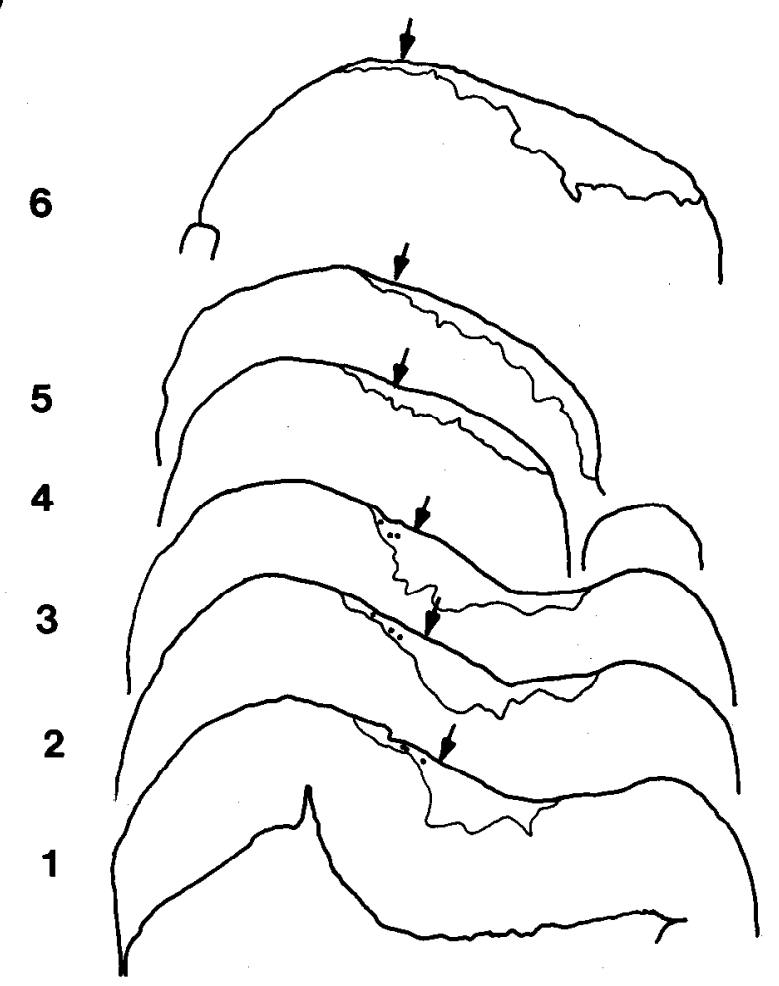

$50 \mu \mathrm{m}$

Figure 5. The pretract extends in front of the leading growth cones. Class 4 embryo. Right eye was labeled with diI. A, A camera lucida drawing of the whole mount, showing the labeled optic axons. The whole mount was sectioned at the planes given by the diagonal lines, and photomosaics of clcctron micrographs of the TPOC/pretract were made. $B$, Tracings of six sections, at the sites indicated in $A$. Only the left half of each section is shown, with the pial boundary up, rostral to the left. The arrows show the boundary between pretract (to the left) and TPOC (to the right). The TPOC and adjacent pretract with labeled optic fibers are evident in sections 1-3; more distally, in sections 4-6, the thin pretract is continued on the rostral boundary of the TPOC. Thus, the pretract appears before the optic growth cones enter it. examined light microscopically (Kevetter and I asek, 1982; Easter and Taylor, 1989).

Pretract (Fig. 6B). Rostral to the TPOC, where the retinal axons advance, the nuclei and their basal cytoplasm were slightly displaced from the basal lamina, but this nucleus-free zone was not primarily axonal. The endfeet were intermediate in size to those in the basal nuclear zone and tract. The space between the endfeet and the somata was made up of fine processes, but their sizes, orientations, and microstructures were different from the TPOC. The pretract processes were larger and more irregular than those in the TPOC, flattened parallel to the pia, with a median area of $0.22 \mu \mathrm{m}^{2}$. Few processes satisfied the ultrastructural criteria for axons (intermediate filaments and/or microtubules parallel to the long axis), so most of the processes are probably cxtensions of the underlying cells (Fig. $4 C$ ), giving the region the texture of a carpet, with the cell processes forming the pile. We have described the structural uniqueness of the pretract, but we emphasize that we have never seen any oriented open extracellular channels of the sort that Singer and others have described (Egar et al., 1970; Nordlander and Singer, 1978; Silver and Robb, 1979; Krayanek and Goldberg, 1981). This exclusion is drawn from electron microscopic examination of numerous clusters of serial sections through the optic stalk [embryos of class $2(n=3)$ and class $4(n=1)$ ], the chiasm [class $2(n=3)$ ], and the diencephalic wall [class $3(n=1)$ and class $4(n=4)]$. The whole mounts (e.g., Fig. 3A) showed a few axons in this region from the THC and the dorsoventral diencephalic tract (DVDT), but these axons did not form any substantial fascicles, nor were they oriented in the direction of growth of the retinal growth cones. Although many new axons are added to the TPOC between 24 and $48 \mathrm{hr}$ (Wilson et al., 1990), they did not apparently enter the pretract. Therefore, the pretract is distinct from the TPOC, not only structurally, but also with respect to the axons that it admits and/or excludes.

\section{Retinal growth cones, and the pretract}

The microenvironment of growth cones inside the pretract was examined electron microscopically. Six leading retinal growth cones were serially sectioned in class 4 embryos $(n=4)$ (Fig. $4 B, C$ ). All were very superficial, within $2 \mu \mathrm{m}$ of the basal lamina, but none contacted the basal lamina directly. A thin endfoot, often only $0.06 \mu \mathrm{m}$ thick, always separated them. Contacts with unlabeled axons were very infrequent. The vast majority of contacts were with somata, processes, and endfeet. For example, one labeled growth cone touched 19 different membranous profiles: 15 neuroepithelial (including three endfeet), three multivesicular bodies (processes of unknown origin that contained numerous vesicles of different sizes), and one unlabeled axon. The axonal contact was traced through serial sections and found to be less than $1 \mu \mathrm{m}$ long. These observations suggest that the leading retinal growth cones were not guided by axons or the basal lamina, but by the basal cellular processes.

\section{Discussion}

\section{Retinal pioneers}

The ventronasal origin of the first axons was unexpected, because the first axons emerge from dorsocentral retina in frog (Grant and Rubin, 1980), chick (Halfter et al., 1985), and mouse (Silver and Sapiro, 1981). This difference is a result of differences in ocular morphogenesis. In frog, chick, and mouse, the optic cup resembles the leaf of a water lily, as the ventrotemporal and ventronasal edges of the optic cup grow symmetrically 

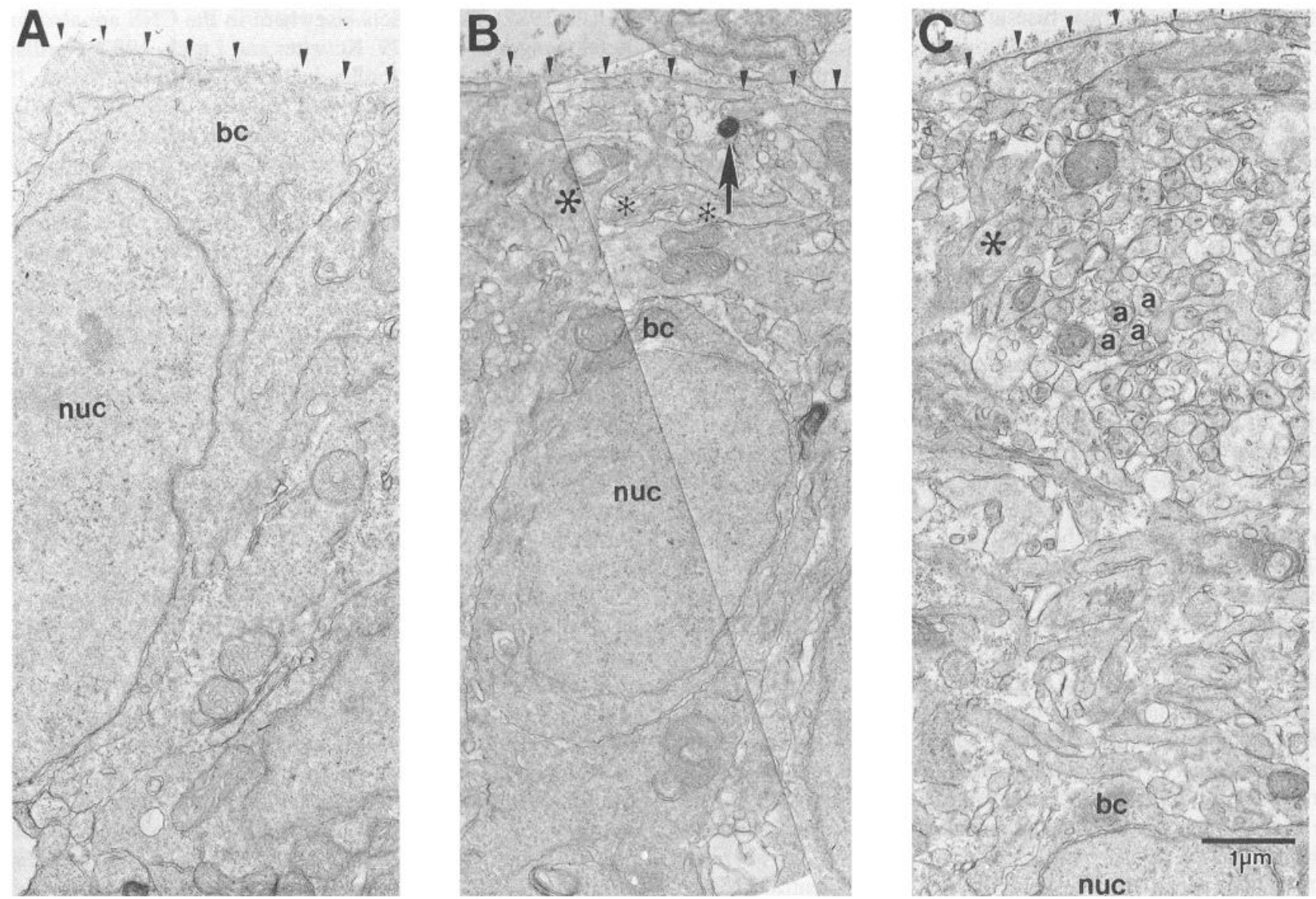

D

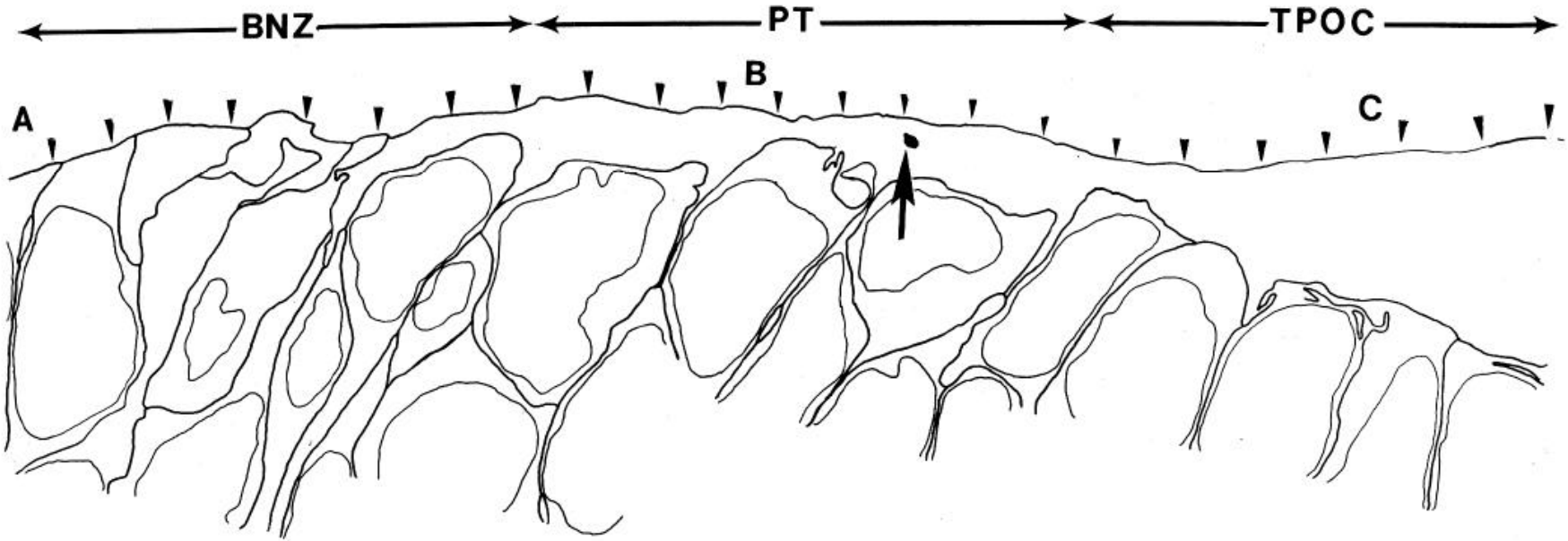

$10 \mu \mathrm{m}$

Figure 6. The three subpial environments shown in sections cut perpendicularly to the TPOC in a class 4 embryo. $A-C$ are electron micrographs, and $D$ is a tracing of the electron microscopic photomosaic that indicates the locations of $A-C$. $A$, In the basal nuclear zone (BNZ), the plasma membrane bounding the basal cytoplasm $(b c)$ of the neuroepithelial soma abuts directly against the basal lamina (arrowheads), and the nucleus $(n u c)$ is also nearby. There are no processes between the soma and the basal lamina. B, In the pretract, the basal cytoplasm and nucleus are displaced from the basal lamina, here about $3 \mu \mathrm{m}$, and this space is filled with neuroepithelial processes (e.g., *), of various shapes and sizes, median area, $0.22 \mu \mathrm{m}^{2}$. The labeled filopodium of the leading optic growth cone is indicated by the arrow. $C$, In a tract, the TPOC, the nucleus, and basal cytoplasm are displaced further from the basal lamina, here about $10 \mu \mathrm{m}$, than in the pretract. The tract includes abundant axons (e.g., $a$ ) cut transversely, and neuroepithelial processes (e.g., $\left.{ }^{*}\right)$ cut in all orientations, median area $0.10 \mu \mathrm{m}^{2}$. The nucleus (nuc) and basal cytoplasm $(b c)$ of the neuroepithelial soma are displaced from the basal lamina (arrowheads) by about $10 \mu \mathrm{m}$. $D$, The boundaries of the three zones are indicated by the horizontal arrows, the locations of the panels by the letters $A-C$, and labeled filopodium by the arrow. 
around the stalk, and then fuse at the embryonic fissure. Thus, the presumptive dorsocentral retina is adjacent to the optic stalk in the earliest eye cup, and the retina adjacent to the embryonic fissure is the last to form. In contrast, the zebrafish optic cup grows differently, as Schmitt and Dowling (1994) have shown. The presumptive embryonic fissure appears early, but oriented obliquely relative to the stalk, with the result that in the earliest eye cup, the future ventronasal quadrant is adjacent to the optic stalk. Thus, in the four vertebrate classes that have been examined, the first axons emerge from those ganglion cells whose progenitors lay closest to the optic stalk. Another feature common to the leading ganglion cells in frog, chick, and mouse is their age; the dorsocentral retinal ganglion cells are the first to withdraw from the mitotic cycle (frog, Jacobson, 1968; chick, Fujita and IIorii, 1963; mouse, Sidman, 1961). The quadrantal location of the first ganglion cells in zebrafish is unknown, but cones first hecome postmitotic in the ventral retina, at ahout 48 hr (Kljavin, 1987; Larison and Bremiller, 1990), suggesting that the ventral hemiretina is the earliest to form.

The orderliness of the development of retinal ganglion cells is impressive. Most withdraw their apical process at about the same time that they extend an axon, and the dendrites begin to form soon thereafter (as in Xenopus; Holt, 1989). New ganglion cells are recruited smoothly in the dorsotemporal direction along an arc that eventually closes the circle at the embryonic fissure, and then more ganglion cells are added outside this circle, in peripheral retina. Differentiation of the dendrites follows a similar spatiotemporal pattern. Nearly all of the ganglion cell bodies are in the proper ganglion cell layer; their dendrites are restricted quite accurately to the inner plexiform layer; and, as we have shown elsewhere (Burrill and Easter, 1994), the central projections are extremely accurate, with practically no projections that later disappear. Such error-free development agrees with other reports that described the topographic accuracy of early retinotectal terminations in zebrafish (Stuermer, 1988; Kaethner and Stuermer, 1992).

The number of leading axons, 4-10, was quite consistent in embryos of classes $2-4$, whether estimated by retrograde or anterograde tracing. This suggests that growth cones from the same population of ventronasal cells may lead the way from the optic cup to the tectum. This, in turn, raises the perennial question of whether the retinal pioneers are, in some respect, different from those that normally follow. Work from Xenopus suggests that they are probably not uniquely able to navigate. Holt (1984) made heterochronic "compound eyes" in which the dorsal hemiretina (whose axons are normally the first to arrive in the tectum) was removed and replaced by one from a younger embryo, whose growth cones emerged later than normal. Growth cones from the remaining host retina grew out on their own, located the tectum, and terminated in the topographically correct sites, despite the absence of predecessors.

\section{Substrates for axonal growth}

The growth cones of the group of leading retinal axons were always very superficial, within $2 \mu \mathrm{m}$ of the pial surface. The retinal growth cones are also superficial in a variety of other species including fish (Bodick and Levinthal, 1980; Easter et al., 1984; Maggs and Scholes, 1986), frog (Constantine-Paton, 1978; Harris et al., 1985; Easter and Taylor, 1989), chick (Suboro et al., 1979; Rager, 1980; Krayanek and Goldberg, 1981; McLoon, 1985), and mammals (Silver and Sapiro, 1981; Silver and Rutishauser, 1984; Bovolenta and Mason, 1987; Guillery and
Walsh, 1987). Early tracts elsewhere in the CNS are also superficial (Singer et al., 1979; Kevetter and Lasek, 1982; Nordlander and Singer, 1982a,b; Nordlander, 1984; Dodd and Jessel, 1988; Dodd et al., 1988; Lumsden and Keynes, 1989; Easter and Taylor, 1989; Wilson et al., 1990; Wilson and Easter, 1991a,b), which suggests that the superficial region must contain substrates favorable to growth cone advance. [Two notable exceptions to this generalization do exist, however: the mammalian corticothalamic and thalamocortical projections are both pioneered more deeply (McConnell et al., 1989; DeCarlos and O'Leary, 1992).] The three anatomical substrates that are available superficially to the retinal growth cones are the basal lamina, the preexisting axons of the TPOC and the THC, and the basal processes of the cells forming the wall of the neural tube. The basal processes are the most likely, for the reasons given below.

Basal lamina. This structure contains molecules that promote axonal outgrowth in vitro (Jessel, 1988), and, therefore, it seemed a likely candidate as an axonal substrate. Previous work on the involvement of the basal lamina has been mixed. Retinal growth cones contact it extensively in the retina and optic nerve of adult fish (Easter et al., 1984; Maggs and Scholes, 1986), but not in embryos of other animals (Harris et al., 1985; Williams et al., 1986, 1991; Bork et al., 1987; Guillery and Walsh, 1987). Although initial retinal axons contacted the basal lamina in the optic stalk, none of those examined in the brain contacted the basal lamina, so we have excluded it as a possible substrate or a source of guidance in the formation of the optic tract.

Preexisting axons. The axons most likely to guide the retinal growth cones were those of the TPOC, as Easter and Taylor (1989) proposed. But the experimental study of Cornel and Holt (1992) raised serious doubts about that conclusion, and the present study has shown that the retinal growth cones scarcely ever contact the TPOC axons, so in this particular case, we can exclude them. The THC axons preceded the retinal growth cones in the region of the pretract, but their trajectories do not lead along the path of the future optic tract, and the retinal growth cones made practically no contacts with axons in the pretract. Therefore, they cannot have provided a substrate, and they are unlikely to have provided guidance.

Basal processes. They are present everywhere in the neural tube, and by the exclusion of the first two alternatives, the basal processes must be considered the most likely substrates and sources of guidance. We have found that growth cones react differentially to two different regions of the neural tube, the TPOC and the pretract. Once the pretract was present, retinal growth cones entered it and avoided the TPOC, whereas nonretinal growth cones entered the TPOC (Wilson and Easter, $1991 \mathrm{~b})$ and avoided the pretract. Thus, the pretract and the TPOC are distinguished as different, despite their close proximity to one another. What is the pretract, and how general is it likely to be?

\section{The pretract: function, origin}

The pretract is almost certainly an example of what Katz and Lasek (1981) called a "substrate pathway," an aligned set of guidance cues. These authors transplanted Mauthner neurons to ectopic sites in the brain and noted that their axons always grew along certain reproducible routes that Mauthner axons would normally never encounter, implying that these routes had some special feature(s) suitable for axonal growth. The present article adds to this operational definition by documenting a substrate 

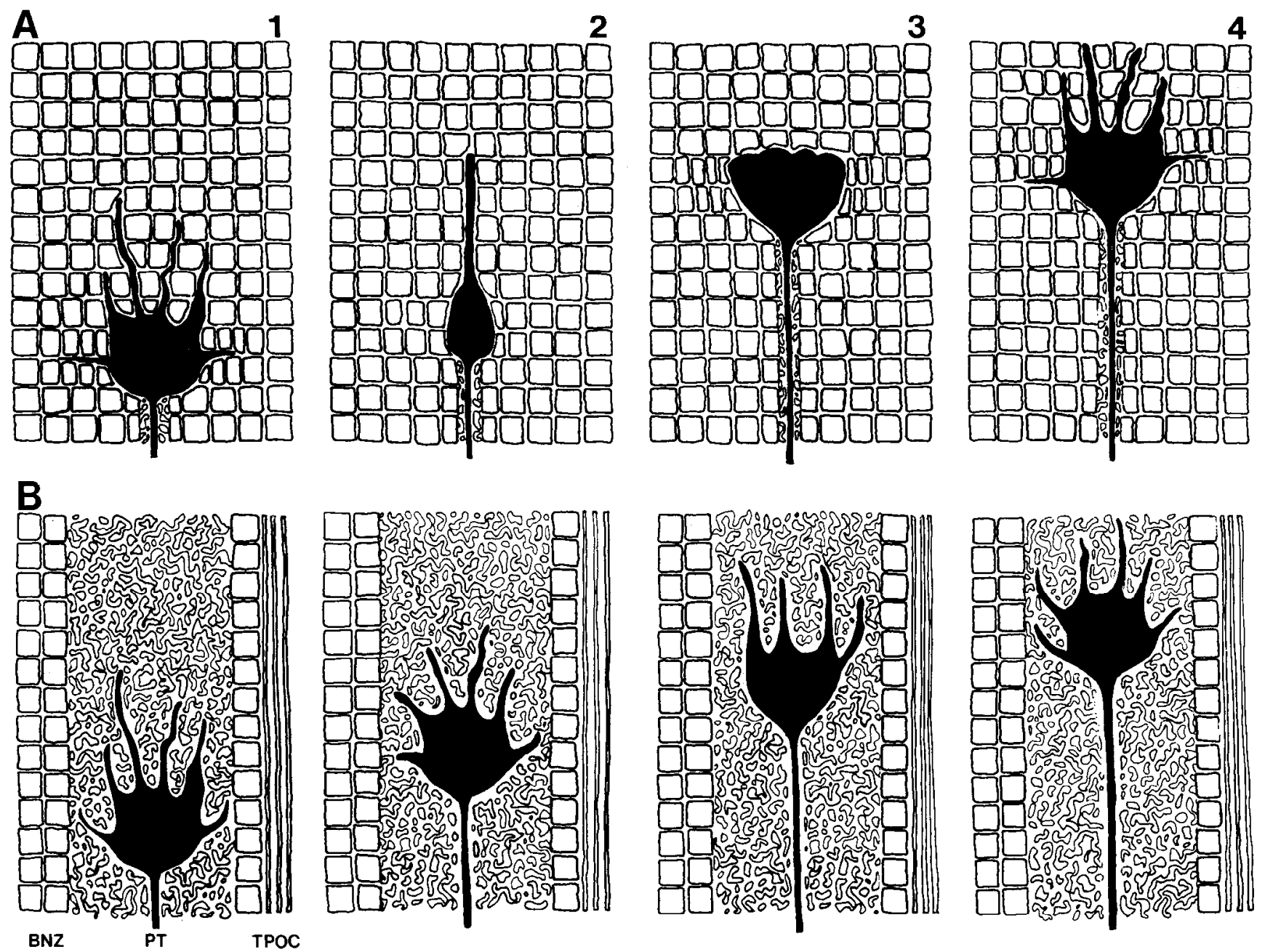

Figure 7. An hypothetical schematic view contrasts growth cone advance through the basal nuclear zone $(A)$ and the pretract $(B)$. The viewpoint is from the pial surface, looking at the plane of the growth cone. $A l$, The flattened growth cone squashes cells laterally and sends filopodia into the interstices between the cells of the neuroepithelial colonnade (represented by the squares; compare Fig. $5 C$ ). It cannot advance in its flattened form because the cells, attached to the basal lamina, present immovable obstacles. A2, Advance requires the growth cone to reduce to a lance-like morphology, withdrawing all filopodia but one and extruding cytoplasm into it. $A 3$, As the growth cone reaches a new location, it expands and flattens, and then (A4) sends filopodia into the interstices, reproducing $A 1$ at a more advanced location. Thus, in the basal nuclear zone, the flattened morphology is associated with immobility, the lance morphology with advance. B1-B4, In contrast, in the pretract, the growth cone is not constrained by immovable cellular pillars but, instead, confronts a lawn of fine processes that are unanchored to the basal lamina. The growth cone can advance through these compliant processes without assuming the lance morphology.

pathway that is selective-it admits retinal axons but not TPOC axons, and it is structurally distinct from the surrounding tissue-the basal processes are modified. Their filamentous morphology suggests that they would be more easily displaced by advancing growth cones than the pillar-like processes (the bowling pins) of the basal nuclear zone (compare Fig. $6 A, B$ ). If so, then the different structures of basal nuclear zone and pretract predict different modes of growth cone advance. In the basal nuclear zone, a cell colonnade anchored to the basal lamina would require the growth cone to periodically assume a lancelike morphology to advance (Fig. 7A), whereas a well-spread growth cone could advance steadily and unimpeded in the pretract (Fig. 7B).

This novel mechanical view accords with our current knowledge. In the basal nuclear zone, the growth cone is typically several cell diameters wide, and it extends filopodia and lamellipodia around several of the neuroepithelial cells (Wilson and Easter, 1991a), presumably sampling the different locations, as in Figure $7 \mathrm{Al}$. If the growth cone were to advance in its spread form, it could grow along the superficial surfaces of the basal endfeet, in contact with the basal lamina, as in adult fish (Easter et al., 1984). But this was never seen in the embryonic brains that we examined. Instead, the growth cone was always separated from the basal lamina by endfeet, indicating that the neuroepithelial cells maintained their contact with the basal lamina. The growth cone may amputate the basal ends of the neuroepithelial cells, scythe like, and advance while maintaining its broad morphology, but we know of no evidence for severed basal processes. The alternative, shown in Figure 7A2, is to transiently change morphology to a lance-like form, squeezing its cytoplasmic contents into a single leading process between neuroepithelial cells and expanding again at a more distal location (Fig. 7A3). Recent evidence from both fish (Kaethner and Stuermer, 1992) and mouse (Wang et al., 1993) supports this interpretation. In both of these studies, living growth cones were visualized in real time, and shown to advance in a saltatory 
fashion, the pauses associated with the broad form of the growth cone, the advances associated with the lance-like morphology. If the filamentous processes of the pretract are not attached to the basal lamina, as our electron micrographs indicate, then the growth cones would be free from the need to change shape periodically, and could advance in a nonsaltatory way, as Figure $7 B$ illustrates. Physical constraints like those described here may yet account for site-specific differences in growth cone morphology in other systems where spread growth cones correlate with slowed advance (e.g., Tosney and Landmesser, 1985).

This mechanical hypothesis provides one possible explanation of the pretract, but it is not the only one. An alternative is that the numerous membranous processes increase the availability of guidance molecules, local cues followed by the retinal pioneers (Harris, 1989). If these guidance molecules were membrane bound, they will be more abundant in a milieu filled with membranous processes.

What produces the pretract? Its extension in front of the leading growth cones suggests that they do not produce the pretract by physical contact with neuroepithelial cells, but the possibility remains that they secrete a diffusible agent that could produce it. That may occur, but it seems unlikely because other pioneering growth cones in zebrafish were not preceded by a pretract (Wilson and Easter, 1991a,b). An alternative explanation depends on the proximity to the boundary of regions of specific gene expression. Lumsden and Keynes (1989) first noted that axons in the hindbrain tended to grow in the interrhombomeric boundaries, and Wilson et al. (1993) have extended this idea to the prechordal brain of zebrafish, where regulatory genes are expressed in patches. The TPOC forms on the boundary of the pax-6 expression territory (Wilson et al., 1993); perhaps the same influences that caused the TPOC to appear there also cause the appearance of the pretract. A second alternative is that other axons already in place produce the pretract, perhaps by releasing diffusible signalling molecules. Although it is nearby, the TPOC is not a good candidate because there was no pretract on the caudoventral side of the TPOC, as would be expected if diffusion were symmetrical. The THC and the DVDT are more likely. Although their axons are not numerous, they are in the appropriate position, and Wilson and Easter (1991a) showed that neuroepithelial basal processes were modified in the wake of the growth cone's passage, in the presence of new axons. This is our preferred hypothesis, that the THC and DVDT growth cones and/or their axons have caused the pretract to form.

How general are the pretract and cryptic pioneers? As was noted above, most of the axons added between 24 and $48 \mathrm{hr}$ join the small number of preexisting tracts. In the single case that we have studied, the addition of retinal axons alongside the TPOC, we have found that the retinal axons are from the beginning separate from the TPOC, and what appeared in whole mounts to be a single tract is, in fact, two, the TPOC and the optic tract. We speculate that analogous situations will probably exist in the other tracts of the initial scaffold, and we predict that they, too, will have pretracts alongside, with cryptic pioneers growing through them. The TPOC, the DVDT, and the tract of the posterior commissure are all known to be joined by axons from origins different from those of the pioneers, and all may have pretracts alongside, but this possibility has not been examined.

\section{Conclusion}

We have examined the development of the optic tract in zebrafish, and found that what seemed to be a case of growth cones following axons was, in fact, something quite different. The apparent followers were actually pioneers, as they advanced in a region that was free of axons, adjacent to but separate from the tract. The specialized region through which they grew was morphologically distinct from its surroundings and extended in front of the axons, adumbrating the optic tract. We suggest that such structures, pretracts and cryptic pioneers, will be found elsewhere in developing brains.

\section{References}

Adams JC (1980) Heavy metal intensification of DAB-based HRP reaction product. J Histochem Cytochem 29:775

Bastiani MJ, Raper JA, Goodman CS (1984) Pathfinding by neuronal growth cones in grasshopper embryos: III. Selective affinity of the G growth cones for the P cells within the A/P fascicle. J Neurosci 4:32113228 .

Bastiani MJ, du Lac S, Goodman CS (1986) Guidance of neuronal growth cones in the grasshopper embryo. I. Recognition of a specific axonal pathway by the pCC neuron. J Neurosci 6:3518-3531.

Bate CM (1976) Pionecr neurones in an insect embryo. Nature 260:5456.

Bodick N, Levinthal C (1980) Growing optic nerve fibers follow neighbors during embryogenesis. Proc Natl Acad Sci USA 77:4374-4378.

Bork T, Schabtach E, Grant P (1987) Factors guiding optic fibers in developing Xenopus retina. J Comp Neurol 264:147-158.

Bovolenta P, Mason C (1987) Growth cone morphology varies with position in the developing mouse visual pathway from retina to first targets. J Neurosci 7:1447-1460.

Burrill JD, Easter SS Jr (1994) Development of the retinofugal projections in the embryonic and larval zebrafish (Brachydanio rerio). J Comp Neurol 316:583-600.

Chitnis AB, Kuwada JY (1990) Axogenesis in the brain of zebrafish embryos. J Neurosci 10:1892-1905.

Constantine-Paton M (1978) Central projections of anuran optic nerves penetrating hindbrain or spinal cord regions of the neural tube. Brain Res 158:31-43.

Cornel E, Holt C (1992) Precocious pathfinding: retinal axons can navigate in an axonless brain. Neuron 9:1001-1011.

De Carlos JA, O'Leary DDM (1992) Growth and targeting of subplate axons and establishment of major cortical pathways. J Neurosci 12: 1194-1211.

Dodd J, Jessel TM (1988) Axon guidance and the patterning of neuronal projections in vertebrates. Science 242:692-699.

Dodd J, Morton SB, Karagogeos D, Yamamoto M, Jessell TM (1988) Spatial segregation of axonal glycoprotein expression on subscts of embryonic spinal neurons. Neuron 1:105-116.

du Lac S, Bastiani MJ, Goodman CS (1986) Guidance of neuronal growth cones in the grasshopper embryo. II. Recognition of a specific axonal pathway by the aCC neuron. J Neurosci 6:3532-3541.

Easter SS Jr, Taylor JSH (1989) The development of the Xenopus retinofugal pathway: optic fibers join a pre-existing tract. Development 107:553-573.

Easter SS Jr, Bratton B, Scherer SS (1984) Growth-related order of the retinal fiber layer in goldfish. J Neurosci 4:2173-2190.

Easter SS Jr, Burrill JD, Marcus RC, Ross LS, Taylor JSH, Wilson SW (1994) Initial tract formation in the vertebrate brain. Prog Brain Res 102:79-94.

Edwards JS, Chen W, Berns MW (1981) Cercal sensory development following laser microlesions of embryonic apical cells in Acheta domesticus. J Neurosci 1:250-258.

Egar M, Simpson SS, Singer M (1970) The growth and differentiation of the regenerating spinal cord of the lizard, Anolis carolinensis. $\mathbf{J}$ Morphol 131:131-152.

Eisen JS, Pike SH, Debu B (1989) The growth cones of identified motoneurons in embryonic zebrafish select appropriate pathways in the absence of specific cellular interactions. Neuron 2:1097-1104.

Fujita S, Horii M (1963) Analysis of cytogenesis in chick retina by tritiated thymidine autoradiography. Arch Histol Jpn 23:359-366.

Godement P, Vanselow J, Thanos S, Bonhoeffer F (1987) A study in developing visual systems with a new method of staining neurons and their processes in fixed tissue. Development 101:697-713.

Grant P, Rubin E (1980) Ontogeny of the retina and optic nerve in 
Xenopus laevis II. Ontogeny of the optic fiber pattern in the retina. J Comp Neurol 189:671-698.

Guillery RW, Walsh C (1987) Changing glial organization relates to changing fiber order in the developing optic nerve of ferrets. J Comp Neurol 265:203-217.

Halfter W, Deiss S, Schwarz U (1985) The formation of the axonal pattern in the embryonic avian retina. J Comp Neurol 232:466-480.

Harris WA (1989) Local positional cues in the neuroepithelium guide retinal axons in embryonic Xenopus brain. Nature 339:218-221.

Harris WA, Holt CE, Smith TA, Gallenson N (1985) Growth cones of developing retinal cells in vivo, on culture surfaces, and in collagen matrices. J Neurosci Res 13:101-122.

Ho RK, Goodman CS (1982) Peripheral pathways are pioneered by an array of central and peripheral neurones in grasshopper embryos. $\mathrm{Na}-$ ture 297:404-406.

Holt CE (1984) Does timing of axon outgrowth influence initial retinotectal topography in Xenopus? J Neurosci 4:1130-1152.

Holt CE (1989) A single-cell analysis of early retinal ganglion cell differentiation in Xenopus: from soma to axon tip. $\mathbf{J}$ Neurosci 9:31233145 .

Honig MG, Hume RI (1986) Fluorescent carbocyanine dyes allow living neurons of identified origin to be studied in long-term cultures. J Cell Biol 103:171-187.

Jacobson M (1968) Cessation of DNA synthesis in retinal ganglion cells correlated with the time of specification of their central connections. Dev Biol 17:219-232.

Jessel TM (1988) Adhesion molecules and the hierarchy of neural development. Neuron 1:3-13.

Kaethner RJ, Stuermer CA (1992) Dynamics of terminal arbor formation and target approach of retinotectal axons in living zebrafish embryos: a time-lapse study of single axons. J Neurosci 12:3257-3271.

Katz MJ, Lasek RJ (1981) Substrate pathways demonstrated by transplanted Mauthner axons. J Comp Neurol 195:627-641.

Keshishian H, Bentley D (1983) Embryogenesis of peripheral nerve pathways in grasshopper legs III. Development without pioneer neurons. Dev Biol 96:116-124.

Kevetter GA, Lasek RJ (1982) Development of the marginal zone in the rhombencephalon of Xenopus laevis. Dev Brain Res 4:195-208.

Kljavin IJ (1987) Early development of photoreceptors in the ventral retina of the zebrafish embryo. J Comp Neurol 260:461-471.

Klose M, Bentley D (1989) Transient pioneer neurons are essential for formation of an embryonic peripheral nerve. Science 245:982-984.

Krayanek S, Goldberg S (1981) Oriented extracellular channels and axonal guidance in the embryonic chick retina. Dev Biol 84:41-50.

Kuwada JY (1986) Cell recognition by neuronal growth cones in a simple vertebrate embryo. Science 233:740-746.

Larison KD, Bremiller R (1990) Early onset of phenotype and cell patterning in the embryonic zebrafish retina. Development 109:567-576.

Letourneau PC (1975a) Possible roles for cell-to-substratum adhesion in neuronal morphogenesis. Dev Biol 44:77-91.

Letourneau PC (1975b) Cell-to-substratum adhesion and guidance of axonal elongation. Dev Biol 44:92-101.

Lumsden A, Keynes R (1989) Segmental patterns of neuronal development in the chick hindbrain. Nature 337:424-428.

Maggs A, Scholes J (1986) Glial domains and nerve fiber patterns in the fish retinotectal pathway. J Neurosci 6:424-438.

Marcus RC, Laster SS Jr (1990) Appearance and distribution of GFAP immunoreactivity in the embryonic zebrafish CNS. Soc Neurosci Abstr $16: 310$.

McConnell SK, Ghosh A, Shatz CJ (1989) Subplate neurons pioneer the first axon pathway from the cerebral cortex. Science 245:978-982.

McLoon SC (1985) Evidence for shifting connections during development of the chick retinotectal projection. J Neurosci 5:2570-2580.

Metcalfe WK (1985) Sensory neuron growth cones comigrate with the posterior lateral line primordial cells in zebrafish. J Comp Neurol 238: $218-224$

Nordlander RH (1984) Developing descending neurons of the early Xenopus tail spinal cord in the caudal spinal cord of early Xenopus. J Comp Neurol 228:117-128.

Nordlander RH, Singer M (1978) The role of ependyma in regeneration of the spinal cord in the urodele amphibian tail. J Comp Neurol 180: 349-374.

Nordlander RH, Singer M (1982a) Morphology and position of growth cones in the developing Xenopus spinal cord. Dev Brain Res 4:181193.
Nordlander RH, Singer M (1982b) Spaces precede axons in Xenopus embryonic spinal cord. Exp Neurol 75:221-228.

Patel NH, Snow PM, Goodman CS (1987) Characterization and cloning of fasciclin III: a glycoprotein expressed on a subset of neurons and axon pathways in Drosophila. Cell 48:975-988.

Pike SH, Eisen JS (1990) Identified primary motoneurons in embryonic zebrafish select appropriate pathways in the absence of other primary motoneurons. J Neurosci 10:44-49.

Piperno (7, Fuller MT (1985) Monoclonal antibodies specific for an acetylated form alpha-tubulin recognise the antigen in cilia and flagella from a variety of organisms. J Cell Biol 101:2085-2094.

Rager G (1980) Development of the retinotectal projection in the chick en. Adv Anat Embryol Cell Biol 63:1-92.

Raper JA, Bastiani MJ, Goodman CS (1983) Pathfinding by neuronal growth cones in grasshopper embryos. II. Selective fasciculation onto specific axonal pathways. J Neurosei 3:31-41.

Reese B, Geller S (1994) Precocious invasion of the optic stalk by transient centrifugal axons in the ferret. Soc Neurosci Abstr 20:1086.

Ross LS, Parrett T, Easter SS Jr (1992) Axonogenesis and morphogenesis in the embryonic zebrafish brain. J Neurosci 12:467-482.

Schmitt EA, Dowling JE (1994) Early eye morphogenesis in the zebrafish, Brachydanio rerio. J Comp Neurol 344:532-542.

Sidman RL (1961) Histogenesis of mouse retina studied with thymidineH3. In: The structure of the eye (Smelser GK, ed), pp 487-505. New York: Academic.

Silver J, Robb RM (1979) Studies on the development of the eye cup and optic nerve in normal mice and in mutants with congenital optic nerve aplasia. Dev Biol 68:175-190.

Silver J, Rutishauser U (1984) Guidance of optic axons in vive by a preformed adhesive pathway on neuroepithelial endfeet. Dev Biol 106: 485-499.

Silver J, Sapiro J (1981) Axonal guidance during development of the optic nerve: the role of pigmented epithelia and other extrinsic factors. J Comp Neurol 202:521-538.

Silver J, Sidman RL (1980) A mechanism for the guidance and topographic patterning of retinal ganglion cell axons. J Comp Neurol 189: 101-111.

Singer M, Nordlander RH, Egar M (1979) Axonal guidance during embryogenesis and regeneration in the spinal cord of the newt: the Blueprint Hypothesis of neuronal pathway patterning. J Comp Neurol 185: $1-22$.

Speidel CC (1933) Studies of living nerves. II. Activities of ameboid growth cones, sheath cells, and myelin segments, as revealed by prolonged observation of individual nerve fibers in frog tadpoles. Am $\mathbf{J}$ Anat 52:1-79.

Stuermer CAO (1988) Retinotopic organization of the developing retinotectal projection in the zebrafish embryo. J Neurosci 8:4513-4530.

Suburo A, Carri N, Adler R (1979) The environment of axonal migration in the developing chick retina: a scanning electron microscopic (SEM) study. J Comp Neurol 184:519-536.

Tosney KW, Landmesser LT (1985) Growth cone morphology and trajectory in the lumbosacral region of the chick embryo. J Neurosci 5:2345-2358.

Wang LC, Godement P, Mason CA (1993) Growth cone form is behavior- and position-specific. Soc Neurosci Abstr 19:620.

Weiss P (1941) Nerve patterns: the mechanics of nerve growth. Growth 5:163-203.

Westerfield M (1989) The zebrafish book. Eugene, OR: University of Oregon.

Williams RW, Bastiani MJ, Lia B, Chalupa LM (1986) Growth cones, dying axons, and developmental fluctuations in the fiber population of the cat's optic nerve. J Comp Neurol 246:32-69.

Williams RW, Borodkin M, Rakić P (1991) Growth cone distribution patterns in the optic nerve of fetal monkeys: implications for mechanisms of axon guidance. J Neurosci 11:1081-1094.

Wilson SW, Easter SS Jr (1991a) A pioneering growth cone in the embryonic zebrafish brain. Proc Natl Acad Sci USA 88:2293-2296.

Wilson SW, Easter SS Jr (1991b) Stereotyped pathway selection by growth cones of early epiphysial neurons in the embryonic zebrafish. Development 112:723-746.

Wilson SW, Ross LS, Parrett T, Easter SS Jr (1990) The development of a simple scaffold of axon tracts in the brain of the embryonic zebrafish, Brachydanio rerio. Development 108:121-145.

Wilson SW, Placzek M, Furley AJ (1993) Border disputes: do boundaries play a role in growth-cone guidance? Trends Neurosci 16:316-323. 